\title{
Tensões, contradições e avanços: a educação de jovens e adultos em uma escola municipal de Belo Horizonte
}

\section{Tensions, contradictions and developments: youth and adult education in a municipal school of Belo Horizonte}

\author{
Leôncio Soares* \\ Ana Rosa Venâncio**
}

\begin{abstract}
RESUMO
Este artigo apresenta as ações destinadas à Educação de Jovens e Adultos da Escola Municipal Aurélio Pires, da Rede Municipal de Ensino de Belo Horizonte-MG. A escola pesquisada possui um projeto de EJA que busca entender e trabalhar as especificidades dos seus sujeitos e, mesmo com todas as dificuldades, procura desenvolver um trabalho que atenda aos jovens e adultos nas suas diversidades e características.

Palavras-chave: educação de jovens e adultos; rede municipal de ensino.
\end{abstract}

\begin{abstract}
This article presents the actions aimed at the adult and young people education of the Municipal School Aurélio Pires, in Belo Horizonte. The school has an EJA project that struggles to understand and to work the specific of their citizens, and even with all the difficulties, tries to develop a work that takes care of the young and adults in their diversities and characteristics.

Key-words: youth and adult education; municipal school.

* Doutor em Educação, professor associado da FaE/UFMG.

** Aluna de graduação em Pedagogia da FaE/UFMG, bolsista de iniciação cientifica
\end{abstract} PROBIC/FAPEMIG. 


\section{Introdução}

"Quem não sabe ler é cego" ${ }^{1}$

A Educação de Jovens e Adultos é uma modalidade de ensino construída a partir da constatação de que os sujeitos socioculturais envolvidos no processo trazem consigo um repertório de vivências e saberes que devem ser tomados como norteadores de suas propostas. Nesse sentido, nos interessou indagar a forma como uma concepção de EJA se fundamenta em uma ação pública e sua implicação no interior de uma escola com uma proposta bem distinta.

Neste texto, procuramos compreender as ações destinadas à Educação de Jovens e Adultos na Escola Municipal Aurélio Pires (EMAP), uma das escolas da Rede Municipal de Belo Horizonte que possui um projeto de EJA buscando entender e trabalhar as especificidades dos educandos, considerando a relevância dessa temática. A pesquisa realizada deu-se no formato de estudo de caso e para tal aconteceram algumas conversas informais com professores responsáveis pelo projeto, além de entrevistas com duas professoras em específico.

\section{Contexto da EJA na Rede Municipal de Ensino de Belo Horizonte}

Segundo os dados preliminares do Censo Escolar 2005/Inep, a matrícula inicial de EJA na cidade de Belo Horizonte é de 19.542 alunos. Desse total, 10.783 matrículas correspondem à dependência municipal, ou seja, mais de $50 \%$ do total.

${ }^{3} 1$ Frase dita pelo Sr. João, 73 anos, aluno da EMAP em uma conversa com o grupo focal. 
A região metropolitana de Belo Horizonte é composta por 34 municípios e, dentre todas essas cidades, escolhemos para estudo de caso a capital mineira, por possuir uma política de Educação de Jovens e Adultos mais consolidada em relação às demais. De acordo com o banco de dados, feito após um levantamento junto a alguns membros do Conselho Municipal de Educação, da Secretaria Municipal de Educação e de professores do Núcleo de EJA da Faculdade de Educação da UFMG, nos 12 municípios $^{2}$ pesquisados da região metropolitana de Belo Horizonte foram localizados 21 projetos/programas de EJA merecedores de destaque e, entre estes, selecionamos o da Escola Municipal Aurélio Pires para estudo de caso.

A EJA, na Rede Municipal de Ensino (RME), tem sua história iniciada em 1971, através da implantação do primeiro curso regular de suplência. Naquela época, o Movimento Brasileiro de Alfabetização, o MOBRAL, era a ação mais significativa no campo da Educação de Adultos no país. Ao longo das décadas de 70 e 80 , a iniciativa de criação de cursos de suplência em Belo Horizonte se deu, sobretudo, por iniciativa da rede particular de ensino e de forma mais tímida pela Secretaria Estadual de Educação. Segundo Soares (1998), ao analisar as estatísticas das redes de ensino do Estado de Minas Gerais, fica evidente a expansão da rede privada na criação dos cursos de suplência. De acordo com os dados de 1991 a 1996 do Conselho Estadual de Educação/MG, dois terços dos cursos de suplência pertenciam à iniciativa privada; a expansão por iniciativa do município acontecerá somente na década de 90.

Em 2000, após o Conselho Nacional de Educação ter homologado as Diretrizes Curriculares Nacionais para a EJA, a Secretaria Municipal de Educação encaminhou ao Conselho Municipal de Educação a solicitação de regulamentação da EJA nas escolas municipais. Esse processo envolveu, principalmente, os trabalhadores em Educação de Jovens e Adultos das escolas municipais, os alunos dessas escolas e representantes de gestores da educação no município.

A primeira grande discussão efetivada pela Câmara de Políticas Pedagógicas acerca da construção das diretrizes para EJA apontou desafios para este Conselho, como o de elaborar uma Resolução representativa das vozes dos sujeitos envolvidos no campo educativo da EJA e o de fazer com que esse processo se constituísse para além das escolas, provocando, na cidade, o debate e a afirmação do direito do jovem e do adulto à educação.

2 Belo Horizonte, Ibirité, Contagem, Sabará, Santa Luzia, Caeté, Itaúna, Lagoa Santa, Nova Lima, Ribeirão das Neves, Sete Lagoas. 
Nesse sentido, algumas ações foram efetivadas, como realização de encontros com representantes dos segmentos e sujeitos envolvidos com a EJA, além de interlocuções com escolas que tinham experiências significativas, debates e visitas a essas escolas.

Tais ações trouxeram contribuições significativas para a elaboração do Parecer CME/2003 para a regulamentação da EJA nas escolas municipais de Belo Horizonte. Esse Parecer representa o resultado de uma conquista dos profissionais e sujeitos envolvidos com a Educação de Jovens e Adultos.

Tal parecer teve por finalidade instituir as diretrizes para a Educação de Jovens e Adultos, sob a forma presencial, nos estabelecimentos de ensino da Rede Municipal de BH, no âmbito do ensino fundamental e médio.

\section{A construção da política de EJA em Belo Horizonte}

O processo de discussão da Educação de Jovens e Adultos na Rede Municipal pautou-se pelo direito à educação e na definição do papel do município na efetivação desse direito. No campo das ações voltadas para a conformação de uma política pedagógica para a EJA na RME-BH, algumas iniciativas mereceram destaque, como a realização, em 1995, de um Seminário de Educação de Jovens e Adultos, cujo objetivo foi o de aprofundar a discussão sobre as dimensões formadoras da vida adulta. Essa discussão evidenciou uma preocupação em romper com a estrutura centrada exclusivamente na transmissão de conhecimentos, demonstrando a sensibilidade dos professores no sentido de entender a vida adulta como um tempo na vida, que tem suas especificidades formadoras com dimensões, saberes, vivências e processos que a diferenciam dos demais tempos de formação, como a infância e a adolescência.

Após esse seminário, vários encontros aconteceram entre os profissionais das escolas, do Centro de Aperfeiçoamento de Profissionais da Educação $(\mathrm{CAPE})^{3}$, da Coordenação Político-Pedagógica e das Regionais para

3 O Centro de Aperfeiçoamento dos Profissionais de Educação, - CAPE, é um órgão da SMED, criado em 1991, responsável pela construção da política da formação dos educadores, norteando suas ações em consonância com o Programa Escola Plural. Desde sua criação, tem atuado no sentido de se tornar uma instância de promoção da formação continuada e em serviço. 
recolher experiências de trabalho e formas de organização mais adequadas aos jovens e adultos. Ações importantes foram concretizadas, advindas das escolas, da Secretaria Municipal de Educação e do Sindicato Único dos Trabalhadores em Educação/Subsede Rede Municipal de BH (Sind-UTE $\mathrm{BH})$ na busca de uma política para a EJA em Belo Horizonte.

A implantação do Programa Escola Plural ${ }^{4}$ causou um grande impacto na história da EJA nas escolas municipais. A preocupação com o direito de permanência de crianças, jovens e adultos em uma escola de qualidade orientou a sua elaboração (SMEd, 1994). O Programa surge, inicialmente, como uma proposta político-pedagógica para o ensino fundamental; no entanto, expressa concepções de natureza política que são referências para toda a educação básica. A Escola Plural, de acordo com SILVA, "provoca modificações estruturais na organização dos tempos e espaços escolares através da constituição dos ciclos de idade de formação, de mudanças no sistema de avaliação e na dimensão curricular" (SILVA, 2005, p. 30).

A $1^{\text {a }}$ Conferência Municipal de Educação, realizada no final de 1994, com o objetivo de apresentar o Programa à cidade, viabilizou, nos horários noturnos, espaços de discussões acerca da EJA. As reflexões coletivas produzidas durante a $1^{\mathrm{a}}$ Conferência evidenciaram a necessidade de se articular uma proposta educacional para essa modalidade da educação básica.

A materialização dos princípios da Escola Plural para a Educação de Jovens e Adultos foi, ao longo dos últimos anos, objeto de discussões da SMEd, em todas as suas instâncias, buscando a construção de uma nova política educacional para esse público. Desde sua implantação, tais discussões foram se concretizando em ações que, em níveis diferenciados, alteraram de forma significativa as práticas das escolas que atendem aos sujeitos jovens e adultos.

Porém, esse programa ainda configura-se como uma política de governo $^{5}$ e, mesmo impondo às escolas a tarefa de construir uma proposta político-pedagógica para a EJA, essa construção se articula à luz do Programa Escola Plural, sendo demarcada historicamente pelas gestões da política educacional do município. Na década de 90, a Rede Municipal de Educação ampliou o número de vagas para a EJA e, apesar das limitações financeiras, o crescimento das matrículas foi bastante significativo em 1997,

4 A Escola Plural foi implantada em 1995 nas escolas municipais de Belo Horizonte. O ensino é organizado em ciclos de idade de formação.

5 Tal política vem se mantendo pelo fato de que, desde a implantação do projeto Escola Plural, em 1995, até o presente governo, 2005, a prefeitura de BH ser administrada por prefeitos do PSB e do Partido dos Trabalhadores. 
quando se fizeram sentir os efeitos da promulgação da Emenda Constitucional $\mathrm{n}^{\mathrm{o}} 14^{6}$. Uma vez o Fundo de Manutenção e Desenvolvimento do Ensino Fundamental e de Valorização do Magistério (Fundef) não contemplando as matrículas de EJA, verificou-se uma clara tendência na RME-BH para a não criação de novos cursos de suplência, acompanhada por um movimento paralelo de transformação de antigos cursos dessa modalidade em ensino fundamental regular comum.

O programa Escola Plural ressalta a necessidade de flexibilização do tempo e do espaço como princípio fundamental na organização do trabalho pedagógico com jovens e adultos. Essa ressignificação não pode ser entendida numa perspectiva simplista da redução do tempo de escolarização, como foi proposto nos processos de supletivização, sendo um aligeiramento, uma aceleração do processo escolar, muitas vezes relacionada a uma improvisação do ensino, comprometendo sua qualidade. Segundo DI PIERRO, 2005:

A cultura escolar brasileira ainda encontra-se impregnada pela concepção compensatória de educação de jovens e adultos que inspirou o ensino supletivo, visto como instrumento de reposição de estudos não realizados na infância ou adolescência. Ao focalizar a escolaridade não realizada ou interrompida no passado, o paradigma compensatório acabou por enclausurar a escola para jovens e adultos nas rígidas referências curriculares, metodológicas, de tempo e espaço da escola de crianças e adolescentes, interpondo obstáculos à flexibilização da organização escolar necessária ao atendimento das especificidades desse grupo sociocultural. (p.1118)

No campo das ações voltadas para a conformação de uma política pedagógica para a EJA na rede municipal de $\mathrm{BH}$, algumas iniciativas merecem destaque, principalmente aquelas postas em prática após a implantação da Escola Plural.

A ampliação do conceito de educação para além da escola, reconhecendo a dimensão educativa de outros espaços de convívio social, foi um

6 A Emenda Constitucional $\mathrm{n}^{\circ} 14$, por exemplo, suprimiu a obrigatoriedade do ensino fundamental de jovens e adultos, excluindo as matrículas do ensino supletivo da base de cálculo para a distribuição das verbas do FUNDEF, mantendo apenas a garantia de sua oferta gratuita. 
princípio proposto e colocado pelos movimentos populares. Tal princípio já se encontra incorporado em alguns dispositivos legais: nos artigos $1^{\circ} \mathrm{e}$ 34 da LDB 9394/96, no Parecer 1132/97 do Conselho Estadual de Educação e no Parecer 5/97 do Conselho Nacional de Educação, que dispõe sobre a Educação Fundamental.

\section{A escolha da Escola Municipal Aurélio Pires}

“já fui cego muito tempo, sabia andar, mas não sabia ler,... ia na cidade e não sabia pegar o bonde,... se não perguntasse alguma pessoa pegava o bonde errado."7

\section{A - Contexto histórico}

A existência da EMAP já passa de meio século, 58 anos de história. Até o final dos anos 60, era uma escola com formação de $1^{\mathrm{a}}$ a $4^{\mathrm{a}}$ séries, depois se transformou em pólo de educação infantil, por passar a atender apenas crianças de 4 a 6 anos. Nos anos 80, a escola volta a ofertar as séries de $1^{\text {a }}$ a $4^{\mathrm{a}}$. No Orçamento Participativo de 1993, a comunidade se mobilizou e conquistou a construção do prédio da escola, uma vez que não possuía endereço fixo até então, motivo pelo qual ocupou três diferentes lugares.

A ação educativa de jovens e adultos na EMAP se inicia no ano de 1995, com três turmas de suplência de $1^{\mathrm{a}}$ a $4^{\mathrm{a}}$ séries. Nesse período, aproximadamente 65 educandos vivenciaram uma experiência escolar organizada de uma forma seriada e demarcada pela semestralidade. A aprendizagem estava num tempo institucional de 90 dias letivos por semestre, distribuídos em quatro horas diárias de aula, organizada em módulos de $50 \mathrm{mi}$ nutos. Assim, a EJA na EMAP nasce integrada aos cursos de suplência

7 Frase dita pelo Sr. João, 73 anos, aluno da EMAP. 
espalhados por todo Estado de Minas, não fugindo à regra de ter como propósito político-pedagógico a recuperação do tempo perdido.

O trabalho desenvolvido até então estava focado no conteúdo acadêmico a ser ensinado de forma rápida e eficaz e não tinha o aluno como sua centralidade. Em 1997, a EMAP passou a atender o ensino fundamental completo, o que serviu também para aumentar o tempo de permanência dos alunos de EJA na escola. Como a escola só tinha autorização para funcionamento da suplência até a $4^{\mathrm{a}}$ série, aqueles alunos adolescentes da EJA que não trabalhavam eram matriculados, se quisessem, no $3^{\circ}$ ciclo diurno da escola para prosseguirem com os estudos.

A Escola Aurélio Pires foi uma das escolas da RME que assumiu a Escola Plural como um desafio e, daí por diante, de acordo com professores da escola, construiu processos pedagógicos que a tornaram vanguarda no movimento de renovação pedagógica pelo qual passou a rede municipal na década de 90 .

\section{$B$ - A Educação de Jovens e Adultos}

Indagações sobre o significado da EJA e sua diferenciação de suplência começaram a surgir nas discussões entre professores, o que provocou muita reflexão e estudo. Tais discussões envolviam também os alunos e foi nesse movimento que educadores e educandos construíram uma nova política para EJA na escola. Nesse sentido, a proposta político-pedagógica da escola começa a ser construída coletivamente com professores e alunos e, segundo Sheilla, professora da escola, esse não foi um processo fácil. Várias dúvidas, conflitos e resistências existiram nas discussões.

Segundo a professora, os educandos também questionavam a reorganização dos tempos escolares, sentiam-se inseguros, temiam ser prejudicados, pois tinham que dividir os tempos da escola, destinando parte desses períodos às discussões de construção da proposta educativa para EJA. Os alunos demonstravam preocupação com o tempo destinado às aulas, respeitavam a importância da sexta-feira como tempo de formação para os professore $^{8}$, mas sugeriam que houvesse aula no primeiro horário e que a reunião dos professores acontecesse no último horário. Apesar de estarem vivenciando um projeto que apresenta uma proposta de tempo escolar dife-

8 A proposta político pedagógica da Escola Plural estipulava que as sexta-feiras seriam dedicadas a momentos de formação dos professores. 
rente, ainda carregavam consigo a idéia de escola em que os tempos são rígidos e inflexíveis.

Na trajetória da EJA na EMAP, segundo Sheilla, o tempo, o espaço e o currículo configuram-se como questões de polêmicas discussões. Para alguns professores, era difícil lidar com outra lógica que não fosse a da seriação e da organização do trabalho por disciplina. Nessa perspectiva, é recorrente nos sistemas de ensino a tentativa de transportar a organização escolar ofertada à criança para a Educação de Jovens e Adultos.

Para tentar lidar com essas questões que afligiam a escola, o envolvimento da mesma no movimento de discussões sobre o ensino noturno e a EJA, na rede municipal, articulado nos fóruns convocados, tanto pela SMEd, quanto pelo SIND-UTE, foi de fundamental importância. Além disso, construiu-se também uma parceria com os professores da Universidade Federal de Minas Gerais (UFMG) ligados ao Núcleo de Educação de Jovens e Adultos (NEJA) da Faculdade de Educação (FaE) e uma interlocução com o Projeto de Educação de Trabalhadores (PET).

A proposta da EJA foi gradativamente sendo construída e transformada na Aurélio Pires. Essa transformação é resultado da realização de projetos de trabalhos temáticos e de oficinas optativas. Na primeira semana do ano letivo, ocorre na escola uma movimentação de acolhida dos alunos e, durante toda a semana, esses alunos são reagrupados para discussões, reflexões e para a construção da proposta de trabalho e dos princípios do Projeto de EJA/EMAP. Nesse momento, é iniciada a construção do Projeto Perfil.

Esse Projeto constitui-se em um conjunto de questões construídas pelo coletivo de alunos e professores, procurando constatar o interesse dos educandos no que se refere às atividades e conteúdos que gostariam de ver presentes na proposta curricular da EJA. Dessa forma, os educadores têm disponível um instrumento para a reflexão e compreensão dos caminhos que podem percorrer na construção do trabalho, tendo como referências a diversidade, as possibilidades, as necessidades e desejos dos sujeitos da EJA.

Outra transformação, para a construção da proposta de uma EJA para a EMAP, foi a mudança do horário de início das aulas de 18:00 para as 19:00 horas. Pelo fato de serem alunos trabalhadores, a primeira hora aula não era vivenciada pelos mesmos. A utilização integral do tempo escolar correspondente às sextas-feiras para formação docente também contribuiu para bons resultados, assim como a flexibilização do tempo do móduloaula (SILVA, 2005) e o rompimento com a suplência. 
A freqüência, com o projeto, tornou-se um dado de avaliação no processo de formação do aluno, desconsiderando a antiga dualidade aprovação/reprovação. Sua apuração cumpre papel relevante na descrição, na avaliação e no planejamento das ações educativas, ela é indicadora de fluxo temporal dos educandos e objeto de constantes discussões entre a equipe docente da EJA (SILVA, 2005, p. 84). As faltas, quando acumulavam cinco consecutivas sem justificativas, levavam o coletivo docente a se comunicar com esses alunos para saber as causas desse afastamento (segundo as professoras, geralmente saúde, trabalho, filhos, violência) e estes acabavam por retornar à escola.

Em 2001, formou-se o primeiro grupo de alunos para a constituição da EJA no período da manhã. Essa turma surge na perspectiva de atender funcionários da escola, trabalhadores que não tinham acesso à escola mesmo estando dentro dela. Ela vem, também, atender a vários alunos que, em alguns períodos do ano, têm seu horário de trabalho alterado. Outros interessados são vigilantes, donas-de-casa que não podem se ausentar de casa à noite, além de alunas mais idosas que no inverno não freqüentavam as aulas. Estas se sentiram inseridas e passaram a usufruir dessa possibilidade de não interrupção dos estudos. Essa turma é caracterizada pela heterogeneidade, do aluno que não lê nada ao que já freqüentou em algum período a escola.

\section{$C-A$ juventude}

Dentre as 8 turmas que iniciaram em 2005, uma é de juventude. Essa turma foi formada porque quando a SMEd decidiu que seriam fechadas turmas, um dos argumentos era que esse projeto era de idosos, não aceitando a juventude. A definição da turma de juventude deu-se, também, pela dificuldade dos professores de lidar com esse grupo específico de alunos, pois possuíam uma inserção no projeto muito diferente dos demais, bem característica da idade, 16 e 17 anos. Porém, de acordo com alguns professores, eles têm aprendido e gostado de trabalhar com esses jovens, descobrindo suas paixões, o que gostam de fazer e assim desenvolvem o projeto de acordo com seus interesses.

Um exemplo dessas atividades é o projeto sobre sexualidade desenvolvido pelas professoras Sheila Alves e Simone Trigueiro em 2005. Para esse trabalho as educadoras recorreram a várias linguagens, como a cinematográfica, plástica e pictórica, abordando o processo de mudanças física e psicológica e a construção social da identidade sexual do jovem. 


\section{$D$ - Contradições da política de EJA}

Ao final do ano de 2004, de acordo com a EMAP, houve uma política de redução de turmas de EJA por parte da SMEd. De um quadro de 10 turmas a escola deveria passar a ter somente 5. No entanto, após algumas negociações com a Secretaria Municipal de Educação, a direção da escola conseguiu aumentar de 5 para 7 turmas. De acordo com a professora Sheila, para a escola isso representou um ganho, é para nós isso foi um ganho, pois se a gente tivesse ficado quietos no nosso lugar, seriam 5 e nós conseguimos fechar o ano com 7, e esse era um número que não tinha negociação.

Para não perder as turmas, os professores, juntamente com alguns alunos da EJA, ao final de 2004 resolveram fazer uma divulgação nos bairros e comunidades em torno da escola sobre o projeto de EJA da EMAP. Os alunos foram ao encontro de amigos, familiares e até desconhecidos, divulgando a Educação de Jovens e Adultos. Os professores, em carro de som, percorreram as ruas do bairro e visitaram igrejas e associações distribuindo folhetos informativos e divulgando a EJA na escola.

Em função dessa mobilização, muitos foram os candidatos que compareceram à escola para se matricular na EJA. O fato colaborou para pressionar a SMEd, conseguindo a autorização para abrir mais uma turma. A escola já havia conseguido ampliar para 7 e com a procura significativa dos alunos conseguiram abrir mais uma. Assim, o ano de 2005 inicia-se com 8 turmas de EJA, sendo uma delas no período da manhã.

Segundo o coordenador do Núcleo de EJA da SMEd, Jerry Adriane, a Prefeitura não fechou nenhuma turma de EJA, pelo contrário, ampliou o atendimento em espaços fora das escolas (Projeto EJA-BH). O que houve foi um reordenamento das vagas de 2004 para 2005, remanejando essas de algumas escolas sem demanda para outras com mais demanda.

De acordo com Jerry, a prefeitura, ao final de 2004, tinha capacidade para atender a 10.500 alunos na EJA, com recursos próprios, sem o financiamento do FUNDEF. Estavam matriculados cerca de 28.000 alunos; os demais 18.000 foram encaminhados para o Ensino Regular Noturno com flexibilização de tempo e carga horária para dar conta das especificidades dos sujeitos jovens e adultos. Esta foi uma estratégia para atender a esse público e conseguir financiamento do FUNDEF. Segundo a secretaria, não existe um fechamento de turmas, apesar de várias estarem muito esvaziadas, pois as escolas ainda não conseguiram superar a "evasão". 
Sobre o ensino médio para os alunos da EMAP, sempre ao final do terceiro ciclo chega a todos os educandos uma ficha para que preencham indicando para qual escola querem ir. Como não há vagas para todos os alunos da EJA, a estratégia da escola é de matricular todos os alunos possíveis para que possam continuar a estudar. Para a direção da escola, se a conversa com a prefeitura quanto ao número de matrículas já é difícil, com o Estado é impossível, pois a política da Rede Estadual inclui primeiro o aluno dentro da faixa etária estabelecida para o ensino médio e, só então, o restante das vagas são destinadas para a EJA.

\section{E- Interrupções}

O mês de maio de 2005 foi marcado pela greve das escolas municipais da capital mineira, o que trouxe alguns impactos do ponto de vista dos alunos matriculados na EJA, pois muitos não retornaram à escola. De acordo com Sheila, a greve levou a escola a perder um número considerável de alunos: a freqüencia na época estava boa, as salas estavam cheias, muito cheias mesmo, depois nós perdemos quase 50\% dos nossos alunos. A greve faz com que o aluno interrompa sua freqüência à escola. Como, para os alunos da EJA, dirigir-se todos os dias à escola significa um sobreesforço depois de uma jornada de trabalho, outros apelos, como ir para casa descansar, namorar, sair com os amigos, passam a desestimular o retorno à escola.

Nesse período, também foi lançada pelo Governo Federal a proposta do Pró-Jovem e alguns alunos migraram da escola. Um dos atrativos do programa é a bolsa oferecida. Segundo Sheila, é a questão financeira, pois a maior parte dos jovens está à procura do primeiro emprego e precisa ajudar a família. Um outro atrativo é a formação técnica que o projeto se propõe a oferecer.

Quanto aos alunos que pertencem à sala da juventude, segundo a direção da escola, a evasão para o Pró-Jovem não foi muito grande, uma vez que o núcleo que atendia àquele projeto estava muito distante, requerendo dos alunos gastar o dinheiro da bolsa para pagar a condução. De acordo com as professoras, essa é uma turma em que os cuidados são maiores e que os alunos demonstraram bastante interesse e gostam da escola, como até então não gostavam, ou sempre gostaram só que nunca tiveram certeza. As professoras procuraram esclarecer aos alunos o que significa um projeto, visto que o Governo Federal lançou uma série de projetos nos últimos meses. 


\section{A organização do trabalho na Aurélio Pires}

O trabalho coletivo na EMAP é uma condição importante para elaboração dos projetos desenvolvidos na escola. Sua organização acontece na perspectiva da diversidade de linguagens, colaborando com a construção de projetos interdisciplinares, que conta com momentos coletivos em que todos os professores envolvem-se na mesma atividade, em duplas, trios ou separadamente. Nesse movimento, acontece um dos pontos que orienta a proposta pedagógica, que é a flexibilização na organização das turmas: ora formando dois grandes grupos, ora em grupo único (como nas saídas de ocupação dos diversos espaços da cidade - cinemas, museus, teatros, feiras de livros, festivais de teatro e dança etc.). Dentre essas turmas, há alunos com perfis diferentes, tanto em termos de desenvolvimento de habilidades, quanto em termos de idade, abrangendo adolescentes, jovens e adultos.

Os projetos desenvolvidos, no conceito da escola, constituem-se em uma oportunidade ímpar para a ampliação da concepção de tempo/espaço na Educação de Jovens e Adultos e devem ser entendidos como forma de trabalhos teórico-práticos voltados para o campo de atuação do aluno, no âmbito do trabalho, do lazer, do esporte, da família, da religiosidade, da cultura, da participação em movimentos sociais, sindicais, etc. Esses projetos são desenvolvidos em espaços tanto dentro quanto fora da escola, utilizando recursos como os do cinema para discussão de temas em que os alunos, algumas vezes, se identificam com as histórias e fatos apresentados nesses espaços.

A flexibilização do tempo/espaço do professor e do aluno constitui-se como característica fundamental que deve orientar a definição, o planejamento e a sistematização dos projetos de trabalho. A partir da valorização da experiência extra-escolar do aluno (trabalho e práticas socioculturais) e das tentativas de articulá-las com a educação escolar é que se construirão os projetos.

Os tempos dos alunos da EJA passaram a ser referenciados nos processos vividos pelo educando dentro e fora da escola. $\mathrm{O}$ aluno pode concluir o ensino fundamental em um ano, dois ou em tempo maior que este, independente de ter ou não experiência anterior.

O processo de avaliação da EMAP é contínuo e diagnóstico, não dissociado do processo de ensino-aprendizagem. Seu início acontece a partir da procura do sujeito pelo projeto de EJA e, através de uma entrevista 
inicial e exposição da proposta pedagógica do projeto, professores e alunos avaliam a identificação do sujeito com o mesmo. A avaliação nesse momento é um instrumento importante que tem como objetivo o conhecimento do processo dos alunos para a reflexão de posteriores intervenções 9 .

Os educandos da EJA são sujeitos de múltiplos saberes, que acumulam conhecimento em suas trajetórias de vida, podendo desenvolver inúmeras habilidades e para os educadores da EMAP esse conhecimento dos sujeitos, principalmente os adultos, não está compartimentado em etapas, não podendo ser enquadrado por série ou classificação.

Nesse sentido, a escola buscou, a partir de 2000, a quebra da seriação uma vez que, para os professores, a educação seriada trazia a marca do tempo perdido, que não fazia sentido com o tipo de projeto desenvolvido. Inicialmente, relativizou-se a seriação propondo dois agrupamentos: o do primeiro segmento para o alfabetismo e o segundo, o de aprofundamento e sistematização de estudos. Não havia um tempo definido para cada segmento e o educando poderia mudar de um segmento para outro de acordo com seu processo.

$\mathrm{O}$ aluno pode ser matriculado em qualquer época do ano, o que faz com que a escola se organize para receber esses alunos, criando grupos de apresentação da proposta pedagógica, assim como grupos de acolhida aos novatos. A carga horária corresponde a três horas de trabalho por dia, de segunda à quinta-feira, em regime presencial, considerando as atividades realizadas fora do espaço escolar.

\section{Considerações finais}

A proposta vivenciada pela escola permite entender a EJA como espaços de aprendizagem, alfabetização, socialização, de deixar de ser "cego", enfim, um espaço de inúmeras possibilidades. Através de um projeto político-pedagógico construído de forma coletiva, a EMAP vem trabalhando para que de fato aconteça uma educação não só que atenda o universo do seu público, mas também de qualidade procurando ouvir e considerar as necessidades de seus alunos e alunas.

9 Proposta político pedagógica da EMAP, 2004, p 13. 
Nesse contexto de compreensão das especificidades dos sujeitos, a escola apresenta características que a torna referência ao se falar de EJA em Belo Horizonte, pois desenvolve um trabalho que procura contemplar a multiplicidade e pluralidade desses alunos, rompendo com questões que não contribuem para a organização da EJA, como a não flexibilização dos tempos e conteúdos que não condizem com a realidade desse sujeito. Ao optar por desenvolver trabalhos através de projetos, procura assim repensar algumas questões que não contemplam o sujeito jovem e adulto que quer estudar, mas que as condições das escolas não são favoráveis.

No projeto de EJA/EMAP, a matrícula ao longo de todo o ano favorece ao educando que fica impossibilitado de estudar por algum período, sem que tenha de esperar até o ano seguinte para que volte à escola. Pensando dessa forma, a escola adota a proposta da freqüência flexível, com o cuidado de haver sempre um professor acompanhando o aluno que precisa se ausentar, para que não venha a abandonar a escola.

As organizações dos trabalhos coletivos e trabalhos desenvolvidos pelos professores na escola são importantes para dar conta da diversidade de linguagens, contribuindo para a construção dos projetos interdisciplinares. Esses trabalhos de fato acontecem, ainda que nem todos os professores tenham incorporado essa idéia, encontrando dificuldades em colocá-los em prática.

Alguns alunos também apresentavam resistência quanto ao projeto de EJA e, por não compreenderem a proposta, consideravam que não pudesse dar certo. Para alguns "a escola de verdade deveria ter quadro cheio de matéria, com livro didático e professora $b_{r a v a}{ }^{10}$ ". Essa compreensão apresenta a idéia que esses alunos possuem de escola, construída pelo contato que já tiveram como estudantes ou pais. A convivência entre os jovens e adultos na escola não é algo passiva, existe uma certa tensão na relação entre eles, de falta de compreensão dos momentos vividos de cada idade, o que colaborou com a criação da turma "Juventude". Essa turma foi definida pela dificuldade dos professores em trabalharem com esse grupo de alunos, que possuíam uma inserção no projeto muito diferente dos adultos, pois eram mais barulhentos, segundo os professores, e faziam seu próprio horário, apesar de ser um grupo pequeno.

As definições externas à escola interferem e muito no projeto, como as políticas da SMEd, os programas do Governo Federal, o que contribui para tencionar o ritmo de trabalho dos educadores e educandos.

${ }^{10}$ Frase dita por uma aluna de 60 anos da EMAP. 
Desta forma, vemos a Educação de Jovens e Adultos na EMAP como uma experiência possível no momento, em que mesmo com todas as dificuldades procura desenvolver um trabalho que atenda aos jovens e adultos nas suas diversidades e características.

\section{REFERÊNCIAS}

BRASIL. Lei 9394 - dez 1996. Lei de Diretrizes e Bases da Educação Nacional. Brasília: Ministério da Educação, artigos $1^{\circ}$ e 34, 1996.

MINAS GERAIS. Parecer 1132 - 12 nov. 1997. A Educação Básica, nos termos da Lei 9.394/96. Belo Horizonte.

CONSELHO NACIONAL DE EDUCAÇÃO. Proposta de Regulamentação da Lei 9394/96. Parecer 05/97. Relator: Ulysses de Oliveira Panisset. Brasília, maio 1997.

DI PIERRO, M. C. Notas sobre a redefinição da identidade e das políticas públicas de Educação de Jovens e Adultos no Brasil. Educação e Sociedade, São Paulo, v. 26, n. 92, p. 1115-1139, especial out. 2005.

ESCOLA MUNICIPALAURÉLIO PIRES. Construção coletiva da proposta pedagógica do projeto de Educação de Jovens e Adultos. Belo Horizonte, ago. 2004.

SECRETARIA MUNICIPAL DE EDUCAÇÃO. EJA: a construção de diretrizes político-pedagógicas para a RME/BH. Belo Horizonte, set. 2000.

SECRETARIA MUNICIPAL DE EDUCAÇÃO. O tempo na educação básica de jovens e adultos. Belo Horizonte, mar. 1999.

SECRETARIA MUNICIPAL DE EDUCAÇÃO. Educação Básica de Jovens e Adultos: Escola Plural. Belo Horizonte, 1996.

SILVA, M. C. de F. Bolsos cheios de tempo: uma leitura dos tempos tramados e vividos na educação de jovens e adultos. 2005. Dissertação (Mestrado em Educação) - Faculdade de Educação, Universidade Federal de Minas Gerais. 2005.

SOARES, L. J. G. A Política Educacional de Jovens e Adultos em Minas Gerais (19911996). In: REUNIÃO ANUAL DAANPEd, 21. p.1-18. Caxambu, 1998. (Publicado em disquete).

Texto recebido em 19 de out. 2006

Texto aprovado em 10 de jan. 2007 